in the neurone itself might be the basis of the lesion. Neither hypothesis has much evidence to support it. ${ }^{2}$

Some correlation, however, may be found between the concentration of ALA and the severity of the symptoms. ALA has a chemical structure similar to the neurotransmitter $\gamma$-aminobutyric acid and might possibly be competing for $\gamma$-aminobutyric acid receptor sites. ${ }^{2} 8$ But in experimental systems treatment with ALA has only a modest effect-incompatible with the devastation of neural function seen in patients.

Since deficiency of porphobilinogen deaminase is the primary lesion in acute intermittent porphyria exacerbation of the condition by drugs might reasonably be expected further to diminish directly the activity of that enzyme. Only one drug, carbamazepine, seems to do this. ${ }^{2}$ Most drugs seem to act by altering the control mechanisms of haem biosynthesis (through negative feedback at transcriptional and translational levels) by depleting a conjectural "regulatory haem pool" arising from degradation of hepatic cytochromes, especially P450, during drug detoxification. Other mechanisms have been proposed, and further work is in progress. ${ }^{6}$

These notions have led to the development of a "logical" treatment for acute systemic porphyric attacks-with haematin. Success has been claimed, but further evaluation is needed, and meanwhile intravenous laevulose probably remains the mainstay of treatment. ${ }^{1}$ The most important measure is prevention: avoidance of drugs dangerous in the three susceptible types of porphyria. Such drugs are diverse in chemistry and pharmacology, and the results of screening are not always easy to relate to the patient; but some have been graded for risk and those which are safe defined. ${ }^{2}$ Those established as dangerous now number over 50 and include barbiturates, sulphonamides, anticonvulsants (hydantoins, succinimides), some tranquillisers (for example, meprobamate), the antidiabetic sulphonylureas, and certain non-steroidal anti-inflammatory agents (for example, phenylbutazone). Safe drugs include chlormethiazole, chlorpheniramine, chlorpromazine, propranolol, aspirin, pethidine, and morphine.

Overproduction of ALA and porphobilinogen by a patient with porphyria always indicates a potential drug hazard. But a distinction must be made between the chemicals and drugs that provoke acute systemic attacks in the three porphyrias mentioned above and agents which merely aggravate or precipitate porphyria but not acute attacks. This is illustrated by porphyria cutanea tarda, where overproduction of ALA and acute systemic attacks do not occur; among the agents which may aggravate or precipitate the condition are oestrogens, ethyl alcohol, iron, and polychlorinated aromatic compounds. Furthermore, patients with porphyria cutanea tarda are susceptible to acute liver disturbance from chloroquine, which is turned to therapeutic advantage when given in a prolonged low dose regimen. ${ }^{9}$ This relatively common type of porphyria has diagnostic "porphyric" skin symptoms, no neurological features, and is associated with accumulation (urinary) of uroporphyrin and depression of uroporphyrinogen decarboxylase. In porphyria cutanea tarda it is quite safe to prescribe barbiturates (sedative or anaesthetic), tranquillisers, antiepileptics, and other drugs contraindicated in acute porphyrias. This also applies to the erythropoietic types of porphyrias.

Such varying drug sensitivity highlights the importance of correct diagnosis. Laboratory methods are paramount and entail quantitative assay of urinary porphobilinogen and ALA for confirmation of the attack of acute porphyria. Porphyrins may also be assayed quantitatively in urine and stool for differential diagnosis of the type of porphyria. Other assaysfor example, of enzyme activity in the haem biosynthetic path- ways-are not essential in acute attacks, but in acute intermittent porphyria these methods may be useful for identifying doubtful or latent disease and in family studies.

I A Magnus

Professor of Photobiology,

Institute of Dermatology,

London E9 6BX

${ }^{1}$ Brodie MJ, Goldberg A. Acute hepatic porphyrias. Clin Haematol 1980; 9:253-72.

2 Moore MR, Disler PB. Drug-induction of the acute porphyrias. Adverse Drug Reactions and Acute Poisoning Reviews 1983;2:149-89.

${ }^{3}$ Doss M, von Tiepermann R, Schneider J, Schmid H. New type of hepatic porphyria with porphobilinogen synthase defect and intermittent acute clinical manifestation. Klin Wochenschr 1979;57:1123-7.

${ }^{4}$ Nordman I, Grandchamp B. Coproporphyria hereditaria. Endocrinologia Clinica y Metabolismo 1983;2:58-66.

${ }^{5}$ Elder GH. The porphyrias: clinical chemistry, diagnosis and methodology. Clin Haematol 1980;9:371-98.

${ }^{6}$ de Matteis F. Las porfirias experimentales como modelos de las porfirias hepaticas humanas. Endocrinología Clinica y Metabolismo 1983;2:67-78.

${ }^{7}$ Moore MR. Laboratory investigation of disturbances of porphyrin metabolism. Association of Clinical Pathologists' Broadsheet 1983;No 109:1-15.

${ }^{8}$ Kramer S. Porphyria variegata. Clin Haematol 1980;9:303-22.

${ }^{9}$ Malina L, Chlumský J. Antimalarika v léčbě pozdni kožni porfyrie. Česk Dermatol 1973;48:381-6.

\section{Can we assess the effects of acupuncture?}

Despite all the recent interest in acupuncture among doctors, scientists, and the public confusion persists about how it works - or indeed if it works at all. ${ }^{1}$ Reviews of the technique have tended to concentrate on the mechanism by which it acts as an analgesic rather than its clinical effect on chronic pain. ${ }^{23}$ Nevertheless, some 20 controlled clinical studies have attempted to evaluate acupuncture, mainly for painful musculoskeletal conditions. These studies divide into three broad categories: acupuncture compared with conventional treatment, ${ }^{4-9}$ acupuncture compared with random insertion of acupuncture needles, ${ }^{10-19}$ and acupuncture compared with a physical placebo. ${ }^{20-23}$ The results give an overall impression that acupuncture has an analgesic effect in about $60 \%$ of patients with chronic pain and that it may be more effective than conventional treatment in some specific conditions such as osteoarthritis of the knee and tennis elbow. ${ }^{6} 9$

These trials have not, however, convinced the sceptics. Most were poorly designed, with small numbers of patients, muddled entry criteria, short follow up, and no clear definition of success or failure. Further studies will be needed to overcome doubts and provide a sound basis for the selection of patients for treatment. But is it possible to design a scientifically sound clinical trial of acupuncture versus conventional treatment?

The answer is that convincing studies are hard to designfor several reasons-but the task is not impossible provided that the problems are recognised. Firstly, acupuncture usually has a sustained analgesic effect, ${ }^{6}{ }^{8}$ but one that is unpredictable; some patients find that pain is relieved for only an hour or two while others (receiving exactly the same treatment) report almost complete relief from pain for as long as one or two years. Secondly, the speed of response varies from an immediate improvement in symptoms to a slowly progressive relief of pain. These two features of acupuncture analgesia make crossover trials virtually impossible, and studies need to be designed on a comparative basis. 
Next, when acupuncture is compared with conventional treatments some sort of physical placebo will be needed. Several studies have compared acupuncture with random needling, assuming it to have only a placebo effect. Such an assumption is probably incorrect. Any noxious stimulus can attenuate pain elsewhere in the body through the mechanism of diffuse noxious inhibitory control. ${ }^{24} 25$ Probably the best available placebo is mock transcutaneous nerve stimulation, which produces a placebo response of the order of $30 \%{ }^{26-28}$ similar to that expected from placebo medication. ${ }^{26} 2930$ The machine may be defunctioned simply by stopping the transmission of current to the patient while allowing its "black box" to produce audio or visual signals. It may therefore be a more suitable physical placebo than random needling, which has a $40 \%$ response rate.

Should a study to compare acupuncture with mock transcutaneous nerve stimulation have different therapists providing the two different treatments ? Such a design might, in effect, compare the charisma of the therapists rather than the treatments. If the same therapist provided both treatments he or she might "sell" one particular treatment in a less convincing way than the other. Both options have faults, but it is difficult to devise a valid placebo which may be used consistently, without the therapist's knowledge.

A further problem with most of the published clinical trials is that too few patients have been entered for a statistically significant result to emerge. Trial size need not be large, however, if two widely different treatments as acupuncture, with a predicted $60 \%$ response rate, versus a physical placebo, with a predicted $30 \%$ response rate, are compared. Clear definitions of success or failure of treatment must be made at the start of the study. Pain returns almost invariably after treatment with acupuncture, and it may be more appropriate to use a survival analysis rather than a comparative statistical test. ${ }^{31}$

Another criticism of some of the previous studies is that they have evaluated the effect of acupuncture on pain without analysing the natural history of different types of pain. ${ }^{16}$ Ideally a single disease should be studied, and the entry criteria should define a relatively homogeneous group of patients.

Acceptable studies of effects of acupuncture as an analgesic should, then, be single blind, comparative trials, initially using a physical placebo, perhaps later comparing the effects of acupuncture with more conventional treatment. If acupuncture is to become an accepted treatment objective scientific studies must be carried out. ${ }^{32}$

\section{GeORGE T LeWITH}

Director,

Centre for the Study of Alternative Therapies,

Southampton SO1 2DG

1 Smith T. Alternative medicine. [Editorial.] Br Med f 1983;287:308.

${ }^{2}$ Anonymous. Endorphins through the eye of a needle. [Editorial.] Lancet $1981 ; \mathrm{i}: 480-2$.

${ }^{3}$ Anonymous. How does acupuncture work? [Editorial.] Br Med $f$ 1981; $283: 746-8$.

4 Fernandes L, Berry H, Clark RJ, Bloom B, Hamilton EBD. Clinical study comparing acupuncture, physiotherapy, injection, and oral antiinflammatory therapy in shoulder-cuff lesions. Lancet 1980 ; $\mathrm{i}: 208-9$.

5 Junnila SYT. Acupuncture superior to piroxicam in the treatment of osteoarthritis. American fournal of Acupuncture 1982;10:241-6.

${ }^{6}$ Milligan JL, Glennie-Smith K, Dowson DI, Harris J. Comparison of acupuncture with physiotherapy in the treatment of osteoarthritis of the knees. In: Conference proceedings of 15th international congress of rheumatology, 1981

${ }^{7}$ Gunn CC, Milbrandt WE, Little AS, Mason KE. Dry needling of muscle motor points for chronic low-back pain: a randomized clinical trial with long-term follow-up. Spine 1980;5:279-91.

${ }^{8}$ Man SC, Baragar FD. Preliminary clinical study of acupuncture in rheumatoid arthritis. $\mathcal{F}$ Rheumatol 1974;1:126-9.
${ }^{9}$ Brattberg G. Acupuncture therapy for tennis elbow. Pain 1983 ;16:285-8.

${ }^{10}$ Matsumoto T, Levy B, Ambruso V. Clinical evaluation of acupuncture. Am Surg 1974;40:400-5.

11 Gaw AC, Chang LW, Shaw L-C. Efficacy of acupuncture on osteoarthritic pain. N Engl f Med 1975;293:375-8.

${ }^{12}$ Lee PK, Andersen TW, Modell JH, Saga SA. Treatment of chronic pain with acupuncture. $\mathcal{F} A M A 1975 ; 232: 1133-5$.

${ }^{13}$ Weintraub M, Petursson S, Schwartz M, et al. Acupuncture in musculoskeletal pain. methodology and results in a double blind controlled trial. Clin Pharmacol Ther 1975;17:248.

${ }^{14}$ Edelist G, Gross AE, Langer F. Treatment of low back pain with acupuncture. Can Anaesth Soc $\mathcal{F} 1976$;23:303-6.

${ }^{15}$ Moore ME, Berk SN. Acupuncture for chronic shoulder pain. An experimental study with attention to the role of placebo and hypnotic susceptibility. Ann Intern Med 1976;84:381-4.

${ }^{16}$ Godfrey CM, Morgan P. A controlled trial of the theory of acupuncture in musculoskeletal pain. $\mathcal{F}$ Rheumatol $1978 ; 5: 121-4$.

17 Co LL, Schmitz TH, Havdala H, Reyes A, Westerman MP. Acupuncture: an evaluation in the painful crises of sickle cell anaemia. Pain 1979;7: $181-5$

${ }^{18}$ Mendelson G, Selwood TS, Kranz H, Loh TS, Kidson MA, Scott DS. Acupuncture treatment of chronic back pain: a double-blind placebocontrolled trial. Am f Med 1983;74:49-55.

${ }^{19}$ Hansen PE, Hansen JH. Treatment of facial pain by acupuncture. Acta Neurochir $1981 ; 59: 279$.

${ }^{20}$ Junnila SYT. Acupuncture therapy for chronic pain: a randomised comparison between acupuncture and pseudo-acupuncture with minimal peripheral stimulus. American fournal of Acupuncture 1982;10:259-62.

${ }^{21}$ Jensen LB, Melsen B, Jensen SB. Effect of acupuncture on headache measured by reduction in number of attacks and use of drugs. Scand f Dent Res 1979;87:373-80.

22 MacDonald AJR, MacRae KD, Master BR, Rubin AP. Superficial acupuncture in the relief of chronic low back pain. A placebo-controlled randomised trial. Ann R Coll Surg Engl 1983;65:44-6.

${ }^{23}$ Lewith GT, Field J, Machin D. Acupuncture compared with placebo in post-herpetic pain. Pain 1983;17:361-8.

${ }^{24}$ Le Bars D, Dickenson AH, Besson JM. Diffuse noxious inhibitory controls (DNIC). I. Effects on dorsal horn convergent neurones in the rat. Pain 1979;6:283-304.

${ }^{25}$ Le Bars D, Dickenson AH, Besson JM. Diffuse noxious inhibitory controls (DNIC). II. Lack of effect on non-convergent neurones, supraspinal involvement and theoretical implications. Pain 1979;6:305-27.

${ }^{26}$ Thorsteinsson G, Stonnington HH, Stillwell GK, Ilveback LR. The placebo effect of transcutaneous electrical stimulation. Pain 1978;5: 31-41.

${ }^{27}$ Lewith GT, Machin D. A randomised trial to evaluate the effect of infra-red stimulation of local trigger points versus placebo on the pain caused by cervical osteoarthrosis. Acupunct Electrother Res 1981;6: 277-84.

${ }^{28}$ Smith CR, Lewith GT, Machin D. TNS and osteo-arthritic pain. Preliminary study to establish a controlled method of assessing transcutaneous nerve stimulation as a treatment for the pain caused by osteoarthritis of the knee. Physiotherapy 1983;69:266-8.

${ }^{29}$ Laurence DR. Clinical pharmacology. 4th ed. Edinburgh: Churchill Livingstone, 1973:ch 4, p 6 .

${ }^{30}$ Beecher HK. The powerful placebo. FAMA 1955;159:1602-6.

${ }^{31}$ George SL, Desu MM. Planning the size and duration of a clinical trial studying the time to some critical event. $\mathcal{f}$ Chronic Dis $1974 ; 27: 15-24$.

${ }^{32}$ Lewith GT, Machin D. On the evaluation of the clinical effects of acupuncture. Pain 1984;16:111-27.

\section{Letters to the editor}

One of the reasons for publishing a scientific paper is to hold it up for critical scrutiny and comment. We believe this comment should be public and immediate, which is why we devote so much space to correspondence. So we are pleased to be receiving more letters for publication, but like all bonanzas it is creating problems. Ten years ago we published more than three quarters of all the letters we received, but now we can publish only half-despite devoting more pages to correspondence. In order to stop the proportion we publish from dropping any lower (and maybe even to raise it) we are going to change our policy. From now on we will shorten some letters ourselves unless authors specifically state that we may not, and authors' willingness to have their letters shortened will inevitably be one factor we will consider when deciding which letters to publish. 